\title{
A STUDY OF SENSITIVITY PATTERN ANALYSIS OF SURGICAL WOUND ISOLATES IN A TERTIARY CARE HOSPITAL
}

\author{
Prasanna Gupta1 ${ }^{1}$ Atul Agrawal ${ }^{2}$
}

${ }^{1}$ Associate Professor, Department of Microbiology, F. H. Medical College, Tundla, Uttar Pradesh. ${ }^{2}$ Associate Professor, Department of Psychiatry, G. R. Medical College, Gwalior, Madhya Pradesh.

\section{ABSTRACT}

\section{BACKGROUND}

The common Health Care Associated Infection (HCAI) as per CDC updated 2007 is UTI (32\%) followed by postoperative wound infections (22\%), nosocomial pneumonia (15\%) and nosocomial septicaemia (14\%).[1]

\section{MATERIALS AND METHODS}

The study was conducted in the Department of Microbiology, Govt. Medical College, Calicut for a period of one year from July 2007 to June 2008. The total number of elective and emergency surgeries done during the one-year period in the three units was 1902 which included 1074 elective (major) and 828 emergency cases. One hundred and two cases of clinically suspected postoperative wound infection (Fifty-nine elective and forty-three emergency) from the above cases was studied in detail. The study included twenty-seven 'clean', thirty-two 'clean-contaminated', thirteen 'contaminated' and thirty 'dirty' cases. Records of these cases were analysed for preoperative antibiotic prophylaxis.

\section{RESULTS}

The commonest microorganism causing wound infection in the study was Staphylococcus aureus followed by Escherichia coli, Pseudomonas aeruginosa and Enterobacter. Klebsiella, Acinetobacter and Serratia was isolated from one case each. Pseudomonas aeruginosa was isolated from 4 cases.

\section{CONCLUSION}

The study was selected to find out the sensitivity pattern of surgical site infection isolates in these patients which is responsible for much morbidity and mortality to patients. The most important isolate in the study was Staphylococcus aureus in clean surgeries. In clean-contaminated, contaminated and dirty surgery cases, multidrug resistant E. coli and Staphylococcus aureus (MRSA) were the main pathogens followed by Pseudomonas, Enterobacter, Acinetobacter and Klebsiella. Antibiotics have a definite role in the treatment of established infections. Development of a suitable antibiotic policy along with proper surveillance programme is essential for our hospital to reduce the postoperative wound infection rates.

\section{KEYWORDS}

Post-Operative Wound Infection, Antibiotic Sensitivity.

HOW TO CITE THIS ARTICLE: Gupta P, Agrawal A. A study of sensitivity pattern analysis of surgical wound isolates in a tertiary care hospital. J. Evolution Med. Dent. Sci. 2017;6(6):448-451, DOI: 10.14260/Jemds/2017/98

\section{BACKGROUND}

It is important to have a clear understanding of the terms used for wound infection. Since 1985 the most commonly used terms have included wound contamination, wound colonisation, wound infection and more recently, critical colonisation. These terms can be defined as: Wound contamination: The presence of bacteria within a wound without any host reaction.[2] Wound colonisation: The presence of bacteria within the wound which do multiply or initiate a host reaction.[2] Critical colonisation: Multiplication of bacteria causing a delay in wound healing, usually associated with an exacerbation of pain not previously reported but still with no overt host reaction.[3,4] Wound infection: The deposition and multiplication of bacteria in tissue with an associated host reaction. [2]

Financial or Other, Competing Interest: None.

Submission 27-12-2016, Peer Review 08-01-2017,

Acceptance 12-01-2017, Published 19-01-2017.

Corresponding Author:

Prasanna Gupta,

Associate Professor

Department of Microbiology,

F.H. Medical College Tundla,

Firozabad, Uttar Pradesh.

E-mail: pramin1414@yahoo.co.in

DOI: $10.14260 /$ jemds $/ 2017 / 98$

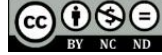

Recognition of wound infection: The inflammatory response is a protective mechanism that aims to neutralise and destroy any toxic agents at the site of injury and restore tissue homeostasis.[5] There are a number of indicators of infection. These include the classical signs related to the inflammatory process and further more subtle changes as highlighted by Cutting and Harding.[6] The classical signs of infection include: Localised erythema, Localised pain, Localised heat, Cellulitis and Oedema. Further criteria include: Abscess, Discharge which may be viscous in nature, discoloured and purulent; Delayed healing not previously anticipated, Discolouration of tissues both within and at the wound margins, Friable, bleeding granulation tissue despite gentle handling and the non-adhesive nature of wound management materials used; Unexpected pain and/or tenderness either at the time change of dressing or reported by the patient as associated specifically with the wound even when the wound dressing is in place; Abnormal smell, Wound breakdown associated with wound pocketing/bridging at base of wound, i.e., when a wound that was assessed as healing starts to develop strips of granulation tissue in the base as opposed to a uniform spread of granulation tissue across the whole of the wound bed. The above criteria should be used as discriminating factors when the 'classic' signs of wound infection do not appear to be present but the presence 
of a wound infection is suspected. Surgical wounds are classified based on the presumed magnitude of the bacterial load at the time of surgery.[7]

According to WHO report 2002, prevalence rate of health care associated infection (HCAI) is 7.7\% - 9\% in developed countries and $10-11.8 \%$ in developing countries. The common HCAI as per CDC updated 2007 is UTI (32\%) followed by postoperative wound infections (22\%), nosocomial pneumonia (15\%) and nosocomial septicaemia $(14 \%) \cdot[1]$

\section{MATERIALS AND METHODS}

Samples were collected from patients with suspected postoperative wound infection, using sterile cotton swabs. The wound was thoroughly irrigated with sterile normal saline until all visible debris had been washed away. Care was taken not to clean the wound with Betadine or any other antiseptic solution before swabbing the area. The area selected was the highly vascular granulation tissue rather than the yellow fibrous slough. The material was collected by pressing the swab over the clean wound surface to extract tissue fluid as this may contain the potential pathogen. ${ }^{[8,9]}$ Two swabs were collected from each site. One swab was used for direct smear examination after Gram staining. The second swab was subjected to culture and antibiotic sensitivity testing by standard microbiological techniques. The swab was plated on Blood agar and MacConkey's agar. Blood agar plates were incubated in the candle jar $\left(\mathrm{CO}_{2}\right)$ at $37^{\circ} \mathrm{C}$ for 24 hours. A sterile report was given only after 48 hours of incubation. From the culture plates, Gram stained smears were made from different types of colonies after noting the colony characteristics. Identification of bacteria was carried out as described by Koneman's textbook of microbiology (sixth edition).[10].Antibiotic sensitivity testing of the isolates was done by the Stokes method for Staphylococcus and Kirby Bauer method for Gram-negative bacilli. The following antibiotic discs were used for sensitivity testing of Grampositive cocci: Penicillin (10 units), Erythromycin (15 mcg), Gentamicin (10 mcg), Vancomycin (30 mcg), Cefazolin (30 mcg). Oxacillin screen agar was used for Staphylococci. Ampicillin (10 mcg), Gentamicin (10 mcg), Cefazolin (30 $\mathrm{mcg}$ ), Ceftriaxone (30 mcg), Amikacin (30 mcg), Ciprofloxacin ( $5 \mathrm{mcg}$ ) were used for sensitivity testing of Gram-negative bacilli. For Pseudomonas Ceftazidime $(30 \mathrm{mcg}$ ) (HiMedia Laboratories Pvt. Ltd. Mumbai.) was also used. In 50 cases, a repeat swab was taken and processed as there was a delay in wound healing and poor response to treatment. All cases were followed up to the date of discharge. Condition of the wound was noted at the time of discharge from the hospital.

\section{RESULTS}

Total number of surgeries done during the one year period in the three surgical units was 1902 which comprised of 1074 elective and 828 emergency cases. One hundred and two suspected postoperative wounds were studied. Twenty-seven were of the 'clean' type of surgical wounds, thirty-two of the 'clean-contaminated', thirteen of the 'contaminated' and thirty of the 'dirty' cases. The incidence of postoperative wound infection was 5.36\%. Among one hundred and two clinically suspected cases studied, bacteriologically proven surgical site infection was identified in thirty-six patients. The prevalence of infection being 35\% (36/102). In the 'clean' surgical group, five patients developed infection, the prevalence was $18.5 \%$. Prevalence of Infection in the 'cleancontaminated' group was $37.5 \% \quad(12 / 32)$. In the 'contaminated' group, it was $38.5 \%$ (5/13) and in the 'dirty' group it was $47 \%(14 / 30)$. Lowest infection rate was seen in clean surgery followed by clean-contaminated, contaminated and dirty surgeries Out of the thirty-six infected cases, thirtyone cases showed infection with single organism and five cases showed mixed infection.

The pathogenic organisms isolated from the thirty-six cases of wound infection are given below. (Table 1a).

Staphylococcus aureus was isolated from 18 cases, Escherichia coli from 15 cases and Enterobacter from 2 cases. Klebsiella, Acinetobacter and Serratia was isolated from one case each. Pseudomonas aeruginosa was isolated from 4 cases. Five cases showed mixed infection. One case of mixed infection was with three organisms and four cases with two organisms (Table 1c).

\begin{tabular}{|c|c|c|}
\hline Organisms & No. of Isolates & \% of Isolation \\
\hline Staphylococcus aureus & 18 & 43 \\
\hline Escherichia Coli & 15 & 36 \\
\hline Pseudomonas aeruginosa & 4 & 9.5 \\
\hline Klebsiella oxytoca & 1 & 2.3 \\
\hline Enterobacter kobei & 1 & 2.3 \\
\hline Enterobacter intermedius & 1 & 2.3 \\
\hline Acinetobacter baumannii & 1 & 2.3 \\
\hline Serratia marcescens & 1 & 2.3 \\
\hline Total & 42 & 100 \\
\hline
\end{tabular}

The commonest microorganism causing wound infection in the study was Staphylococcus aureus. Staphylococcus aureus was isolated from cases of laparotomy (6), mastectomy (4), gastrectomy (1), abscess incision and drainage (1), APR for Ca rectum (2), paraumbilical hernia with appendicular abscess (1), Trendelenburg operation (1), appendicectomy (2). Fifteen out of the eighteen isolates of Staphylococcus aureus were MRSA. The three Methicillin sensitive Staphylococcus aureus were from the 'clean' surgical group. Seven MRSA were from the 'cleancontaminated', two from the 'contaminated' and six from the 'dirty' group.

Multidrug resistant Gram-negative bacilli were the predominant organisms isolated from the 'cleancontaminated', 'contaminated' and 'dirty' type of surgery.

Escherichia coli was isolated from cases of laparotomy (9), tracheal resection (2), APR for Ca rectum (3), cholecystectomy (1). There was a total of four isolates of Pseudomonas aeruginosa, from cases of laparotomy (3) and Trendelenburg operation (1). Enterobacter was isolated from cases of triple anastomosis (1), hernia repair (1). Klebsiella oxytoca (1) was isolated from a case of laparotomy. Acinetobacter baumannii was isolated from one case of Trendelenburg operation and Serratia marcescens from one 'clean' case of lipoma excision (Table 1b). Repeat swabs were collected after 3-4 days in all culture-positive cases. Same results were obtained except in one case of paraumbilical hernia with appendicular abscess where first swab grew Coagulase-negative staphylococci and repeat swab yielded growth of Staphylococcus aureus (MRSA). 


\begin{tabular}{|c|c|c|c|}
\hline $\begin{array}{l}\text { Type of } \\
\text { Surgery }\end{array}$ & $\begin{array}{c}\text { Infected No. } \\
\text { of Cases }\end{array}$ & $\begin{array}{c}\text { Organisms } \\
\text { Isolated }\end{array}$ & $\begin{array}{l}\text { No. of } \\
\text { Isolates }\end{array}$ \\
\hline \multirow{5}{*}{ Laparotomy } & \multirow{5}{*}{17} & Escherichia Coli & 7 \\
\hline & & $\begin{array}{c}\text { Staphylococcus } \\
\text { aureus }\end{array}$ & 6 \\
\hline & & $\begin{array}{l}\text { Pseudomonas } \\
\text { aeruginosa }\end{array}$ & 2 \\
\hline & & Klebsiella oxytoca & 1 \\
\hline & & $\begin{array}{l}\text { Enterobacter } \\
\text { intermedius }\end{array}$ & 1 \\
\hline Hernia repair & 1 & Enterobacter kobei & 1 \\
\hline Mastectomy & 4 & $\begin{array}{c}\text { Staphylococcus } \\
\text { aureus }\end{array}$ & 4 \\
\hline Appendicectomy & 2 & $\begin{array}{l}\text { Staphylococcus } \\
\text { aureus }\end{array}$ & 2 \\
\hline \multirow{2}{*}{$\begin{array}{l}\text { APR for } \\
\text { Ca rectum }\end{array}$} & \multirow[t]{2}{*}{2} & $\begin{array}{l}\text { Staphylococcus } \\
\text { aureus, }\end{array}$ & 1 \\
\hline & & Escherichia Coli & 1 \\
\hline Abscess I \& D & 1 & $\begin{array}{l}\text { Staphylococcus } \\
\text { aureus }\end{array}$ & 1 \\
\hline Cholecystectomy & 1 & Escherichia Coli & 1 \\
\hline Tracheal resection & 2 & Escherichia Coli & 2 \\
\hline Lipoma excision & 1 & $\begin{array}{c}\text { Serratia } \\
\text { marcescens }\end{array}$ & 1 \\
\hline \multicolumn{4}{|c|}{$\begin{array}{c}\text { Table 1b. Relationship between the Type of Surgery and } \\
\text { Organisms in } 31 \text { cases which were Infected with Single } \\
\text { Organism }\end{array}$} \\
\hline
\end{tabular}

Mixed bacterial infection was observed in five cases. These were three cases of laparotomy, one case of APR for Ca rectum and one case of Trendelenburg operation. Infection with Escherichia coli and Staphylococcus aureus occurred in one case of APR for Ca rectum, and in two cases of laparotomy. Pseudomonas aeruginosa and E. coli mixed infection was seen in one case of laparotomy. Infection with Acinetobacter baumannii, Pseudomonas aeruginosa and Staphylococcus aureus occurred in one case of Trendelenburg operation. (Table 1c).

\begin{tabular}{|c|c|c|}
\hline Type of Surgery & No. & Organisms Isolated \\
\hline $\begin{array}{c}\text { APR for Ca } \\
\text { rectum }\end{array}$ & 1 & $\begin{array}{c}\text { Escherichia coli, Staphylococcus } \\
\text { aureus }\end{array}$ \\
\hline Laparotomy & 2 & $\begin{array}{c}\text { Escherichia Coli, Staphylococcus } \\
\text { aureus }\end{array}$ \\
\cline { 2 - 3 } & 1 & $\begin{array}{c}\text { Pseudomonas aeruginosa, } \\
\text { Escherichia Coli }\end{array}$ \\
\hline $\begin{array}{c}\text { Trendelenburg } \\
\text { operation }\end{array}$ & 1 & $\begin{array}{c}\text { Acinetobacter baumannii, } \\
\text { Pseudomonas aeruginosa, } \\
\text { Staphylococcus aureus }\end{array}$ \\
\hline \multicolumn{2}{|c|}{ Table 1c. Infection with Multiple Organisms } \\
\hline
\end{tabular}

Analysis of the antibiotic sensitivity pattern of the isolates: There were eighteen isolates of Staphylococcus aureus. None of the isolates were sensitive to penicillin and erythromycin. $100 \%$ sensitivity was shown towards vancomycin. There were fifteen isolates of MRSA (Methicillinresistant Staphylococcus aureus). Cloxacillin had 28\% sensitivity. Only three isolates of staphylococcus aureus were Cloxacillin sensitive. $22 \%$ of the isolates were sensitive to gentamicin. Among the isolates of Gram-negative bacilli, none were sensitive to Ampicillin. There were total twenty-four Gram-negative bacterial isolates, twenty-two were multidrug resistant (92\%). Of the Gram-negative isolates, fifteen were Escherichia coli. All the strains were resistant to ampicillin, cefazolin, ceftriaxone, ciprofloxacin. Amikacin had a sensitivity of $73.3 \%$. Ten isolates of E. coli were sensitive only to amikacin, two isolates were sensitive to both gentamicin and amikacin.

\begin{tabular}{|c|c|c|c|c|c|c|c|}
\hline Antibiotic & $\begin{array}{c}\text { S. aureus } \\
18\end{array}$ & $\begin{array}{c}\text { E. Coli } \\
15\end{array}$ & $\begin{array}{c}\text { Enterobacter } \\
\mathbf{2} \\
\end{array}$ & $\begin{array}{c}\text { Pyo } \\
4\end{array}$ & $\begin{array}{c}\text { Kleb } \\
1\end{array}$ & $\begin{array}{c}\text { Serratia } \\
1\end{array}$ & $\begin{array}{c}\text { Acineto } \\
1\end{array}$ \\
\hline Penicillin & Nil & NT & NT & NT & NT & NT & NT \\
\hline Erythromycin & Nil & NT & NT & NT & NT & NT & NT \\
\hline Gentamicin & 22.2 & 13.3 & Nil & 25 & 100 & Nil & 100 \\
\hline Ampicillin & NT & Nil & Nil & NT & $\mathrm{Nil}$ & Nil & $\mathrm{Nil}$ \\
\hline Vancomycin & 100 & NT & NT & NT & NT & NT & NT \\
\hline Cefazolin & 22.2 & Nil & Nil & Nil & Nil & Nil & 100 \\
\hline Ceftazidime & NT & NT & NT & 25 & NT & NT & NT \\
\hline Oxacillin & 27.7 & NT & NT & NT & NT & NT & NT \\
\hline Piperacillin & NT & NT & NT & 25 & NT & NT & NT \\
\hline Amikacin & NT & 73.3 & 100 & 25 & 100 & Nil & 100 \\
\hline Ciprofloxacin & NT & Nil & 50 & 25 & Nil & Nil & 100 \\
\hline Ceftriaxone & NT & Nil & Nil & NT & Nil & Nil & 100 \\
\hline \multicolumn{8}{|c|}{ Table 2. ABST Pattern of the Isolates in (\%) } \\
\hline
\end{tabular}

NT - Not tested

Enterobacter isolates showed $50 \%$ sensitivity towards ciprofloxacin. Only one out of the four isolates of Pseudomonas was sensitive to cephalosporins \& aminoglycosides. The single isolate of Acinetobacter baumannii showed $100 \%$ sensitivity towards amikacin, gentamicin, ciprofloxacin and ceftriaxone. The single isolate of Serratia marcescens was resistant towards the first line antibiotics (ampicillin, gentamicin) and second line antibiotics (amikacin, $3^{\text {rd }}$ generation cephalosporins and ciprofloxacin) that are routinely used for Gram-negative bacilli. All Gram-negative isolates were sensitive to imipenem $(100 \%)$. ESBL was not detected due to limited resources.

\section{DISCUSSION}

The incidence and pattern of wound infection varies from centre to centre. In the present study, the incidence of postoperative wound infection is $5.36 \%$ of the one hundred and two clinically suspected cases of post-operative wound infection studied. Prevalence of infection in the study group is $35 \%$. 


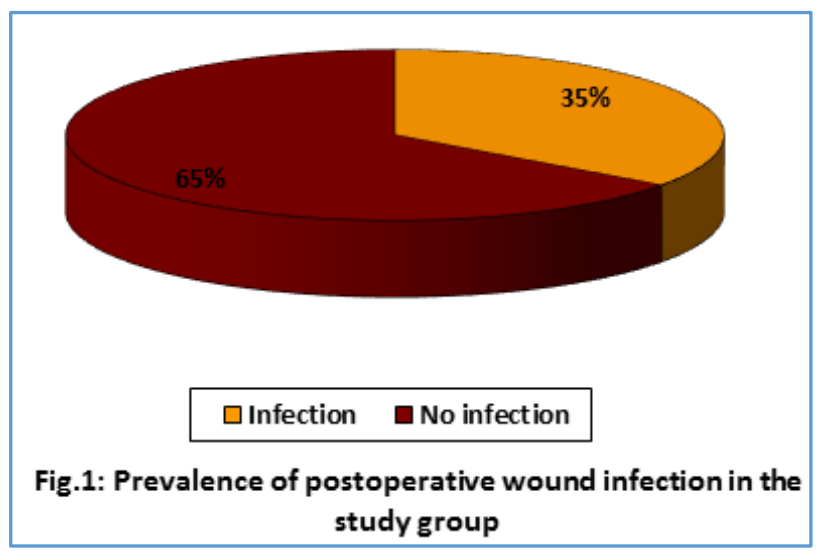

The prevalence of postoperative wound infection among 'clean' cases was $18.5 \%$, 'clean-contaminated' $37.5 \%$, 'contaminated' $38.5 \%$ and 'dirty' $47 \%$.

While the global estimates of SSI have varied from 0.5$15 \%$, studies in India have consistently shown higher rates ranging from $23-38 \%{ }^{11,12}$ In a prospective study of surgical site infections in a teaching hospital in Goa, the overall SSI rate was estimated to be $30.7 \%$. $5.4 \%$ for clean, $35.5 \%$ cleancontaminated and $78.8 \%$ for contaminated operations.[13] Antibiotic sensitivity pattern of the isolates: Penicillin resistance was seen in eighteen of the isolates of Staphylococcus aureus in this study. Erythromycin resistance was also eighteen. Fifteen of the isolates were resistant to Cloxacillin.

None of the Gram-negative bacilli isolated in this study was sensitive to Ampicillin. All the Escherichia coli isolated from wound infection showed multiple resistance. Amikacin sensitivity was $73.3 \%$ for E. coli. One isolate of Escherichia coli, was resistant to all routine antibiotics \& was sensitive to imipenem only. Table 2 explains the ABST of the isolates. In a prospective study of surgical site infections in a teaching hospital in Goa, 79\% of isolates were Gram-negative and almost $64 \%$ demonstrated polyantimicrobial resistance.[13] Data from the NNIS CDC 2007 shows that multidrug resistant Klebsiella, E. coli, Acinetobacter, Pseudomonas, etc. are now the major hospital pathogen. ${ }^{[1,14]}$

Escherichia coli were the most resistant organisms causing wound infection among the Gram-negative bacilli in the present study. Patients in this study belonged to 18 to 83 years of age group. Maximum number of cases were between 15-25 years of age (20 cases) and 46-55 years of age (20 cases). Maximum infection rate was observed in old age, particularly between $76-85$ years of age (67\%). Four out of the six cases in this group got infected.

\section{Sex}

Out of the one hundred and two cases, thirty-two patients were female and seventy patients were male. A slightly higher infection rate of $36 \%(25 / 70)$ was observed in the males compared to $34.3 \%(11 / 32)$ in females. Diabetes, hypertension and anaemia were not observed in majority of the cases. So its influence on wound infection could not be studied in detail.

\section{CONCLUSION}

Postoperative wound infection (surgical site infection) is an important aspect of nosocomial infections which is a serious problem in hospital practice. The study was selected to find out the pattern of postoperative wound infection and the role of antibiotics in these patients which is responsible for much morbidity and mortality to patients. One hundred and two cases of postoperative wounds were studied in detail during the one year period from July 2007 to June 2008 at Calicut medical college. The prevalence rate of post-operative wound infection among study group was 35\%. The most important isolate in the study was Staphylococcus aureus in clean surgeries. In clean-contaminated, contaminated and dirty surgery cases, multidrug resistant E. coli and Staphylococcus aureus (MRSA) were the main pathogens followed by Pseudomonas, Enterobacter, Acinetobacter and Klebsiella. The incidence of post-operative wound infection was 5.36\%. Even the clean category surgery patients received antibiotic prophylaxis which may be the reason for the low incidence of post-operative wound infection. Antibiotics have a definite role in the treatment of established infections. Development of a suitable antibiotic policy along with proper surveillance programme is essential for our hospital to reduce the postoperative wound infection rates.

\section{REFERENCES}

[1] Bai RJT. Hospital infection-present scenario. Proceedings of the fourth triennial conference of the academy of clinical Microbiologists and pre-conference seminar on changing trends in hospital infections 2008:18-23.

[2] Ayton M. Wound care: wounds that won't heal. Nurs Times 1985;81(46):16-9.

[3] Falanga V, Grinnell F, Gilchrest B, et al. Workshop on the pathogenesis of chronic wounds. J Invest Dermatol 1994;102(1):125-7.

[4] Kingsley A. A proactive approach to wound infection. Nurs stand 2001;15(30):50-4, 56, 58.

[5] Collier M. Understanding wound inflammation. Nurs Times 2003;99(25):63-4.

[6] Cutting KF, Harding KG. Criteria for identifying wound infection. J wound care 1994;3(4):198-201.

[7] Martone WJ, Nichols RL. Recognition, prevention, surveillance, and management of surgical site infections: introduction to the problem and symposium overview. Clin Infect Dis 2001;33(Suppl 2):S67-8.

[8] Howe CW. Postoperative wound infections due to staphylococcus aureus. N Engl J Med 1954;251(11):4117.

[9] Pulaski EJ. Discriminate antibiotic prophylaxis in elective surgery. Surg Gynecol Obstet 1959;108(4):3858.

[10] McKittrick LS, Wheelock FC. The routine use of antibiotics in elective abdominal surgery. Surg Gyn Obstet 1954;99(3):376-7.

[11] Ganguly PS, Khan Y, Malik A. Nosocomial infections \& hospital procedures. Indian J Commun Med 2000;25:990-1014.

[12] Subramanian KA, Prakash A, Shrinivas, et al. Postoperative wound infection. Ind J Surg 1973:57-64.

[13] Kamat US, Fereirra AMA, Kulkarni MS, et al. A prospective study of surgical site infections in a teaching hospital in Goa. Indian J Surg 2008;70(3):1204.

[14] National nosocomial infections surveillance system. Centers for disease control and prevention (CDC). Health care associated infection (HCAI) updated 2007. 